\title{
Studies on the effect of antioxidant Selenium-ACE after treatment with Praziquantel and Mirazid in Schistosoma mansoni infected mice
}

\author{
Muhammad Hamdy Emam ; Mona Abd El-Rahman ${ }^{* *}$; Irene Sameh Gamil ${ }^{* *}$ and Marwa \\ Ahmed Muselhy** \\ * Parasitology Department, Faculty of Medicine, Al-Azhar University ${ }^{* *}$ Zoology Department, \\ Faculty of Science, Helwan University
}

\begin{abstract}
:
Background: This study deals with the evaluation of parasitological, histopathological and biochemical effect of Praziquantel (PZQ) and Mirazid (MZ) with or without Selenium-ACE (Se-ACE) on male albino mice infected with S.mansoni and trying to evaluate the antioxidant effect of Se-ACE and its role in reducing the severity of the infection.

Results: The obtained results indicated that treatment with PZQ produced more reduction in worm burden and ova count/gm liver than MZ compared to the infected control group. PZQ showed the highest reduction in liver granuloma number and diameter when compared to $\mathrm{MZ}$ group while both drugs showed a significant effect in restoration of the liver transaminases and protein fractions towards their normal levels indicating the safety of both drugs as anti $S$. mansoni chemotherapeutics, Se-ACE showed a high efficacy as a co-treatment, potentiating the effect of PZQ and MZ in reducing the worm burden, ova count/gm liver, number and diameter of liver granuloma and restoration of liver transaminases and protein fractions to their normal levels during treatment of $S$. mansoni infection.
\end{abstract}

Conclusion: the rank order of potency in protection against liver cell damage was PZQ 500 $\mathrm{mg} / \mathrm{kg}>\mathrm{MZ} 600 \mathrm{mg} / \mathrm{kg}$ where Se-ACE showed a couraging criterion as a co- treatment potentiating the effect of the antischistosomal medications through its anti- oxidant activity.

Keywords: Praziquantel, Mirazid, Selenium-ACE , S. mansoni and co-treatment.

\section{Introduction:}

Schistosomiasis is a chronic and debilitating parasitic disease which affects approximately 200 million people in the developing world and imposes a substantial public health and economic impact, despite the continuous control efforts (Wang et al., 2009). The development of PZQ is considered a hallmark on the path to eradicate the Schistosomal infection (Pearson and Guerrant, 1983). The use of PZQ has been correlated with some side effects such as hyperglycemia, thus, the search for a new effective and safe Schistosomicidal agent is highly encouraged ( El-Hawey $\boldsymbol{e t}$ 
al.,1990) and nowadays the use of natural plant extracts as new safe and effective drugs are needed. The present study is a trial to clarify the antischistosomal effect of commiphora extract (Mirazid) compared to $\mathrm{PZQ}$, and to investigate the role of SeACE as an antioxidant compound when combined with both drugs in reducing the severity of infection. Parasitological, histopathological and biochemical parameters were investigated in liver of $S$. mansoni infected mice

\section{Material and Methods:}

Male albino mice (Mus musculus), aged 68 weeks and weighing 18-20 gm were used in this study. Mice were bred on standard diet with free accessibility to water at the Schistosome Biological Supply Program (SBSP), Theodor Bilharz Research Institute, Giza , Egypt.

Mice were divided into seven groups each of twenty mice. After the normal control group, mice were infected with $70-75$ cercariae by tail immersion technique . One infected group left as a control group, three groups were supplemented by Se-ACE in diet from the first day post infection till eight weeks, after six weeks post infection one of the three groups was treated with PZQ in a dose of $500 \mathrm{mg} / \mathrm{kg}$ body weight on 2 days and another group was treated with $\mathrm{MZ}$ in a dose of $600 \mathrm{mg} / \mathrm{kg}$ on three consecutive days, the third group left on Se-ACE supplementation only. The sixth and seventh groups did not receive $\mathrm{Se}$ -
ACE supplementation in diet. Six weeks post infection, the sixth group received PZQ and the seventh group received $\mathrm{MZ}$ with the same previous doses. Eight weeks post infection, all groups were sacrificed and the male, female, coupled worm, worm burden, egg count, liver granuloma number and diameter, aspartate aminotranferase (AST), alanine aminotransferase (ALT), total proteins (TP) and albumin (ALB) were used as a criterion for studying the effect of these drugs.

Worm counting - Worms were recovered by liver perfusion as described by Smithers and Terry (1965). The worm counting was done by stereomicroscope (

Duvall and De Witt , 1967).

Tissue egg count - eggs were counted by the method of Cheever (1968):

Number of ova in $1 \mathrm{gm}$ liver $=$

(Number of ova in $5 \mathrm{ml}$ ) $\mathrm{x} 1$

Weight of liver in grams recorded before digestion.

Histopathological studies were done according to the method described by Von Lichtenberg (1962):

The mean diameter of each liver granuloma was measured in microns, from two diameters of the lesion taken at right angles to each other with the help of an ocular micrometer. First the greatest diameter of the lesion was obtained, then the ocular micrometer was rotated 90 degrees and the diameter perpendicular to the first one was measured (Von 
Lichtenberg, 1962). According to Boros and Warren (1970), lesion counts between 50-100 were taken into consideration. In this work the volume was obtained by the formula described by Mahmoud and Warren, (1974):

$$
\text { volume of sphere }=\mathrm{R}^{3} \times \frac{4}{3} \times \frac{22}{7}
$$

The radius ( $\mathrm{R}$ ) was obtained by dividing the mean diameter of each lesion by two. The volume thus obtained was in cubic microns, but for the ease of statistical tabulation and graph drawing, the volume was transferred to cubic mm.

\section{Biochemical assays:}

ALB was determined as described by Doumas and Bigges (1972), TP was determined as described by Peters (1968), ALT and AST were determined according to Schmidt (1963) by using Pasteur diagnostics kit , Egypt

\section{Results:}

The results obtained in the present study showed a significant reduction in the mean number of male and female worms in all the infected treated groups compared to the infected untreated group except in the infected Se-ACE -treated group where the reduction was insignificant. There was a significant reduction of coupled worms in all the infected- treated groups compared to the infected control group. These results correlate with the worm burden showing a significant reduction in the mean worm burden of all the treated groups compared to the infected control group and the results showed that a highest reduction of male, female, coupled worms and worm burden was in Se-ACE-PZQ- treated group, and PZQ treated group scoring a complete eradication, followed by Se-ACE -MZtreated group, MZ- treated group and finally Se-ACE - treated group (Table 1 and Fig. 1).

Regarding the ova count, the results obtained showed no significant difference in the mean number of ova count/gm liver between infected control, infected SeACE- treated and infected MZ - treated groups while there was a significant reduction in the mean number of ova count/gm liver in the infected Se-ACEPZQ-treated group followed by PZQtreated group then the infected Se-ACEMZ treated group (Table 2 and Fig. 2).

Regarding the histopathological aspects, the present study revealed a significant reduction in the number of liver granulomas, in all the infected treated groups when compared to the infected control group except for infected Se-ACE treated group where the number of granulomas decreased was yet still insignificant and there is no significant difference in the reduction of the number of hepatic granulomas between the all the infected treated groups. Regarding the granuloma diameter, there was a significant reduction in the infected SeACE -PZQ-treated group, PZQ -treated group and infected Se-ACE-MZ -treated group, where there was no significant reduction of granuloma diameter in the 

infected $\mathrm{MZ}$-treated group and infected

The infected control group (Table 3 and Figs. 3, 4).

The biochemical assay revealed a significant reduction in ALT, AST, ALB and TP in liver homogenates of S. mansoni infected mice indicating a reduction in liver activity due to infection. After treatment with drugs, the results indicated a restoration of liver enzymes ALT and AST near the normal values without any significant difference between the treated
Se-ACE -treated group when compared to groups (Table 4 and Fig. 5), also TP and ALB showed an increase in their values towards the normal levels where the SeACE-PZQ-treated group recorded the highest significant score in the way towards normalization of the TP and ALB levels followed by Se-ACE-MZ -treated group, PZQ- treated group, MZ -treated group and finally the Se-ACE- treated group (Table 4 and Fig. 6).

Table (1): Mean number of worms in the different studied infected groups.

\begin{tabular}{|l|l|l|l|}
\hline \multicolumn{1}{|c|}{ Groups } & \multicolumn{1}{c|}{ Male worms } & Female worms & \multicolumn{1}{c|}{ Couple worms } \\
\hline Control & $6.33 \pm 1.86$ & $3.83 \pm 1.60$ & $7.00 \pm 2.83$ \\
Se-ACE & $6.00 \pm 2.37$ & $4.67 \pm 2.73$ & $4.67 \pm 1.03^{\mathrm{a}}$ \\
Mirazid & $4.50 \pm 1.20^{\mathrm{a}}$ & $1.75 \pm 1.16^{\mathrm{ab}}$ & $4.44 \pm 2.65^{\mathrm{a}}$ \\
PZQ & $0.0 \pm 0.0^{\mathrm{abc}}$ & $0.0 \pm 0.0^{\mathrm{abc}}$ & $0.0 \pm 0.0^{\mathrm{abc}}$ \\
Se-ACE- + PZQ & $0.0 \pm 0.0^{\mathrm{abc}}$ & $0.0 \pm 0.0^{\mathrm{abc}}$ & $0.0 \pm 0.0^{\mathrm{abc}}$ \\
Se-ACE-mirazid & $2.56 \pm 2.19^{\mathrm{abcde}}$ & $0.67 \pm 1.12^{\mathrm{ab}}$ & $3.63 \pm 1.06^{\text {ade }}$ \\
\hline
\end{tabular}

Values are expressed as mean \pm SD or number (\%).

${ }^{a} p<0.05$ relative to infected control group.

${ }^{b} \mathrm{p}<0.05$ relative to infected Se-ACE- group.

${ }^{c} \mathrm{p}<0.05$ relative to infected mirazid group.

$\mathrm{d} p<0.05$ relative to infected PZQ group.

${ }^{\mathrm{e}} \mathrm{p}<0.05$ relative to infected Se-ACE-PZQ group.

(20 albino mice)

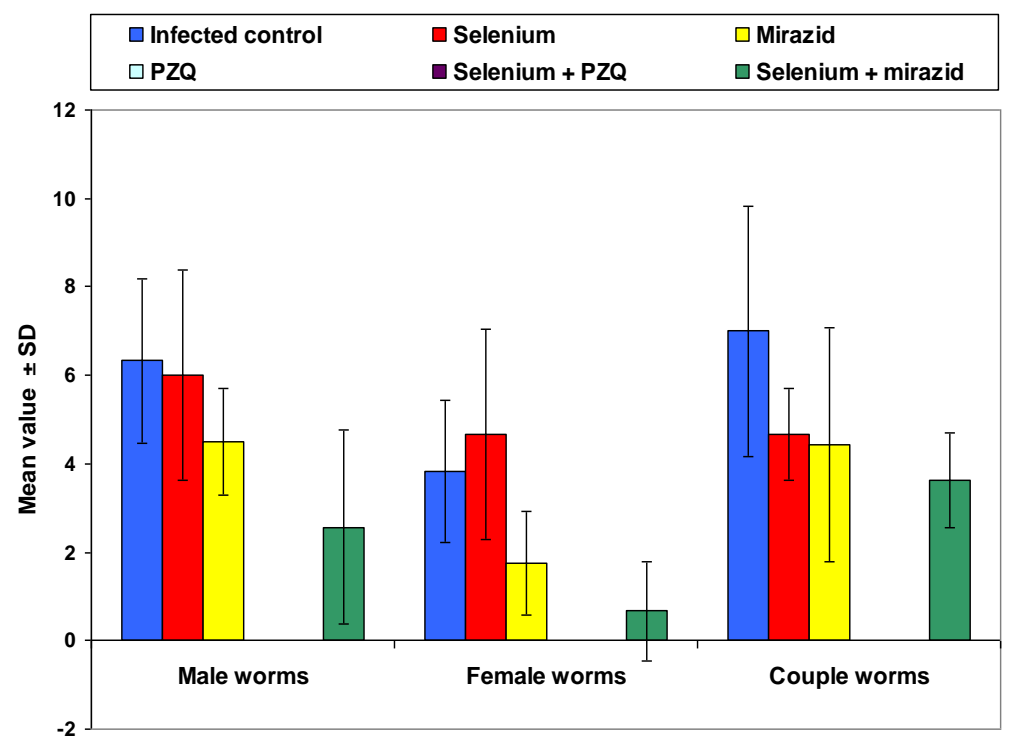

Fig. (1): Mean number of male, female and couple worms in the different studied infected groups. 
Table (2): Mean number of ova count/gm liver in the different studied infected groups.

\begin{tabular}{|l|c|c|}
\hline Groups & Mean \pm SD & $\begin{array}{c}\text { \% reduction in } \\
\text { ova count }\end{array}$ \\
\hline Control & $5571.21 \pm 1910.23$ & --- \\
Se-ACE & $4022.88 \pm 1682.85$ & $27.8 \%$ \\
Mirazid & $4061.71 \pm 1340.19$ & $27.1 \%$ \\
PZQ & $2742.39 \pm 1033.74^{\text {a }}$ & $50.78 \%$ \\
Se-ACE + PZQ & $1855.24 \pm 487.20^{\text {abc }}$ & $66.7 \%$ \\
Se-ACE + mirazid & $3629.36 \pm 1445.93^{\text {ae }}$ & $34.86 \%$ \\
\hline
\end{tabular}

Values are expressed as mean \pm SD or number $(\%)$

${ }^{a} \mathrm{p}<0.05$ relative to infected control group.

${ }^{b} \mathrm{p}<0.05$ relative to infected $\mathrm{Se}-\mathrm{ACE}$ group.

${ }^{c} \mathrm{p}<0.05$ relative to infected mirazid group.

${ }^{\mathrm{e}} \mathrm{p}<0.05$ relative to infected Se-ACE + PZQ group.

(20 albino mice)

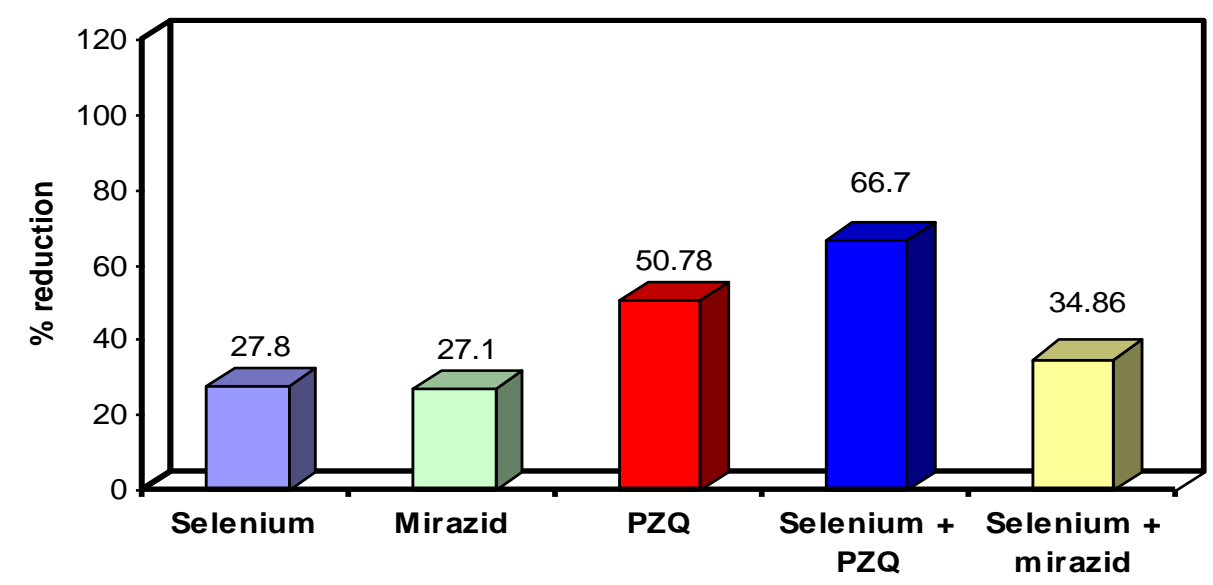

Fig. (2): Percent reduction in the mean number of ova count/gm liver in the different studied infected groups.

Table (3): Mean granuloma count and diameter in different studied infected groups.

\begin{tabular}{||c|c|c|c|c|}
\hline \multirow{2}{*}{ Groups } & \multicolumn{2}{|c|}{ Granuloma count } & \multicolumn{2}{c|}{ Granuloma diameter } \\
\cline { 2 - 5 } & Mean & $\begin{array}{c}\% \\
\text { reduction }\end{array}$ & Mean & $\begin{array}{c}\% \\
\text { reduction }\end{array}$ \\
\hline Control & $6.88 \pm 1.9$ & --- & $230.12 \pm 36.29$ & --- \\
Se-ACE & $4.93 \pm 1.45$ & $28.34 \%$ & $207.46 \pm 28.7$ & $9.85 \%$ \\
Mirazid & $4.7 \pm 0.76^{\mathrm{a}}$ & $31.69 \%$ & $193.3 \pm 37.98$ & $16 \%$ \\
PZQ & $4.1 \pm 1.2^{\mathrm{a}}$ & $40.41 \%$ & $179.73 \pm 17.52^{\mathrm{a}}$ & $21.9 \%$ \\
Se-ACE + PZQ & $3.2 \pm 1.19^{\mathrm{a}}$ & $53.49 \%$ & $165.17 \pm 22.09^{\mathrm{a}}$ & $28.22 \%$ \\
Se-ACE + mirazid & $4.5 \pm 1.18^{\mathrm{a}}$ & $34.59 \%$ & $182.46 \pm 18.6^{\mathrm{a}}$ & $20.71 \%$ \\
\hline
\end{tabular}

Values are expressed as mean \pm SD or number $(\%)$

${ }^{a} \mathrm{p}<0.05$ relative to infected control group. 
Studies on the effect of .....

(20 albino mice)

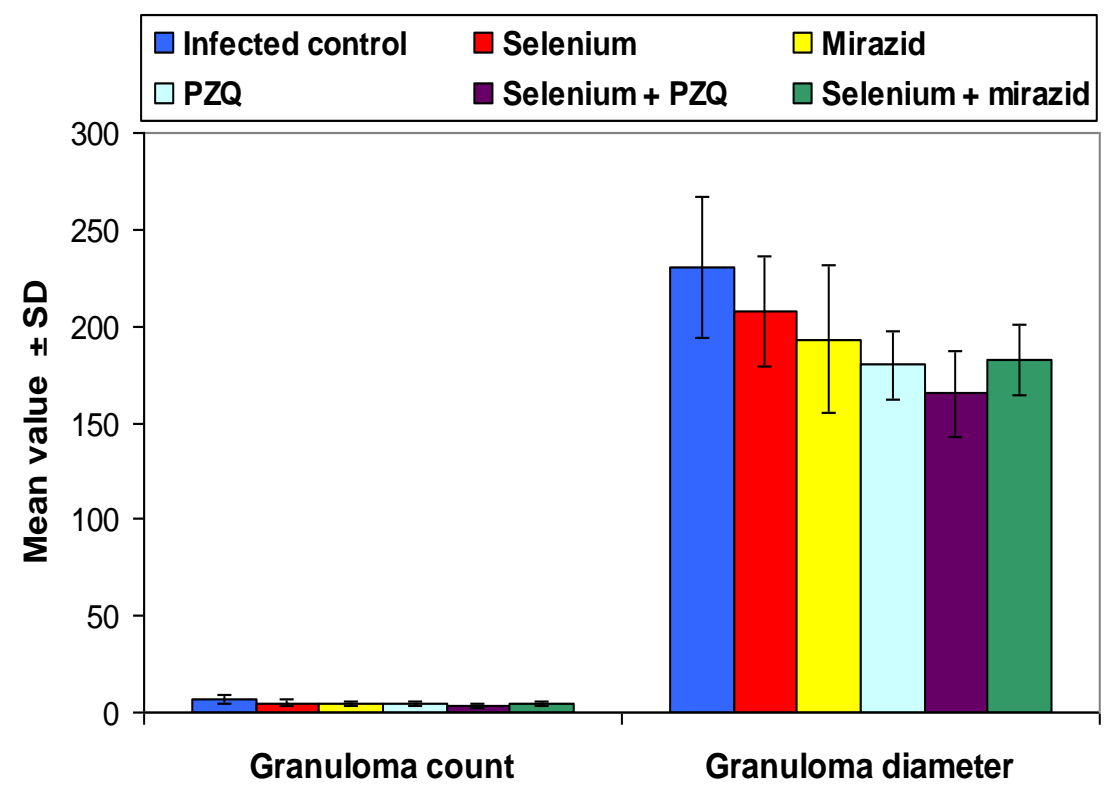

Fig. (3): Mean hepatic granuloma count and diameter in the different studied infected groups.

Table 4: Mean values of ALT, AST, TP and ALB in the different studied groups.

\begin{tabular}{|l|c|c|c|c|}
\hline \multicolumn{1}{|c|}{ Groups } & ALT & AST & TP & ALB \\
\hline Normal control & $114.4 \pm 9.6$ & $110.2 \pm 7.1^{\prime}$ & $6.16 \pm 0.34$ & $3.62 \pm 0.16$ \\
Infected control & $64.7 \pm 8.7^{\mathrm{b}}$ & $71.5 \pm 10.1^{\mathrm{b}}$ & $4.95 \pm 0.62$ & $2.42 \pm 0.48$ \\
Infected Se-ACE treated & $105.1 \pm 6.01^{\mathrm{a}}$ & $103 \pm 4.3^{\mathrm{a}}$ & $6.79 \pm 0.31^{\mathrm{a}}$ & $3.19 \pm 0.27^{\mathrm{a}}$ \\
Infected Mirazid treated & $103.2 \pm 7.1^{\mathrm{a}}$ & $100.1 \pm 11.6^{\mathrm{a}}$ & $6.4 \pm 0.73^{\mathrm{a}}$ & $3.46 \pm 0.93^{\mathrm{a}}$ \\
Infected PZQ treated & $104.1 \pm 8.5^{\mathrm{a}}$ & $101.3 \pm 12.4^{\mathrm{a}}$ & $6.67 \pm 0.48^{\mathrm{a}}$ & $3.50 \pm 0.15^{\mathrm{a}}$ \\
Infected Se-ACE + PZQ treated & $111.3 \pm 6.8^{\mathrm{a}}$ & $106.2 \pm 11.3^{\mathrm{a}}$ & $7.70 \pm 0.58^{\mathrm{ac}}$ & $3.67 \pm 0.38^{\mathrm{a}}$ \\
Infected Se-ACE + mirazid & $106.2 \pm 7.9^{\mathrm{a}}$ & $104.4 \pm 8.6^{\mathrm{a}}$ & $6.95 \pm 0.98^{\mathrm{a}}$ & $3.64 \pm 0.60^{\mathrm{a}}$ \\
treated & & & & \\
\hline
\end{tabular}

Values are expressed as mean \pm SD.

${ }^{a} \mathrm{p}<0.05$ relative to infected control group.

${ }^{\mathrm{b}} \mathrm{p}<0.05$ relative to normal control group.

${ }^{c} \mathrm{p}<0.05$ relative to infected $\mathrm{MZ}$ group.

(20 albino mice) 



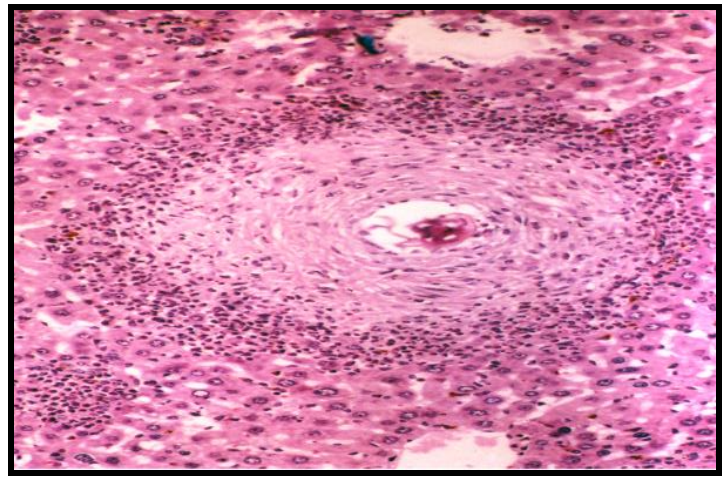

(4a)

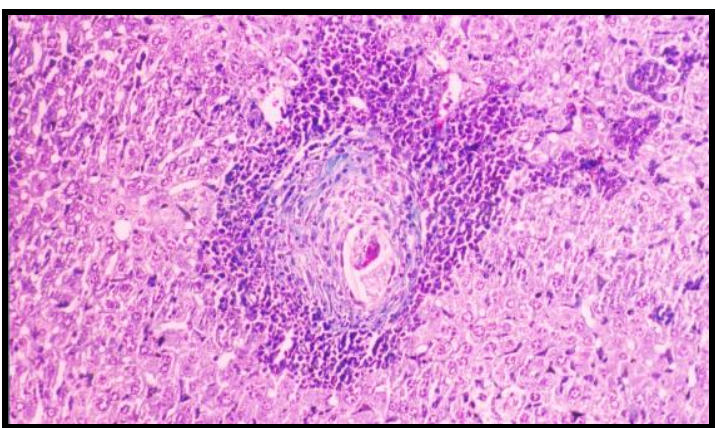

$(4 c)$

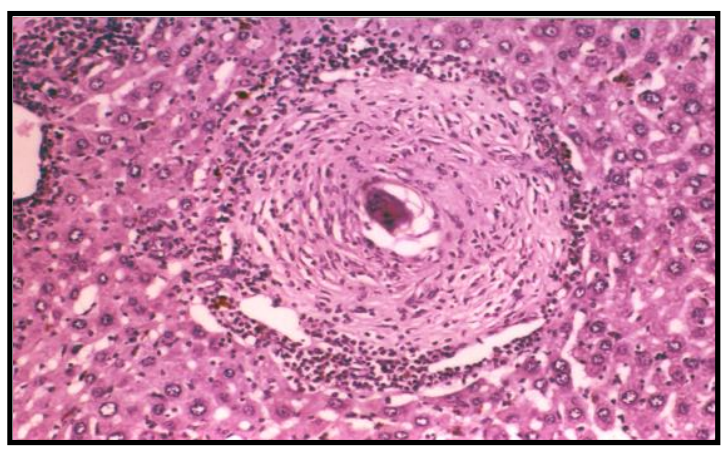

$(4 \mathrm{e})$

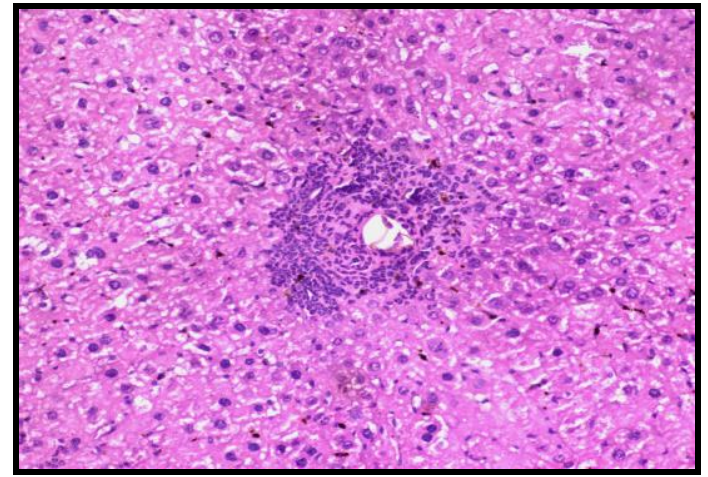

(4b)

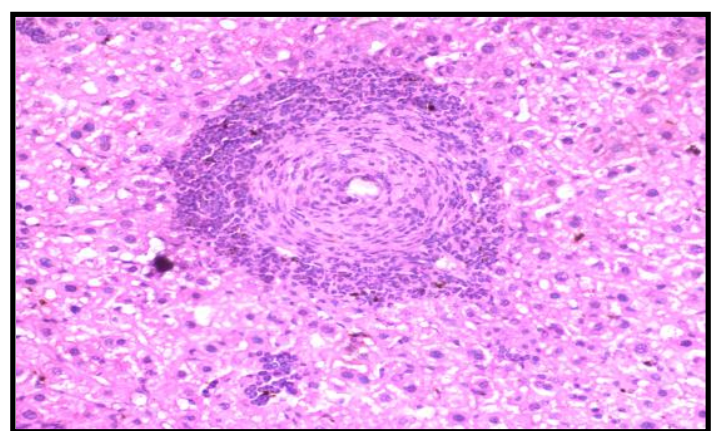

$(4 d)$

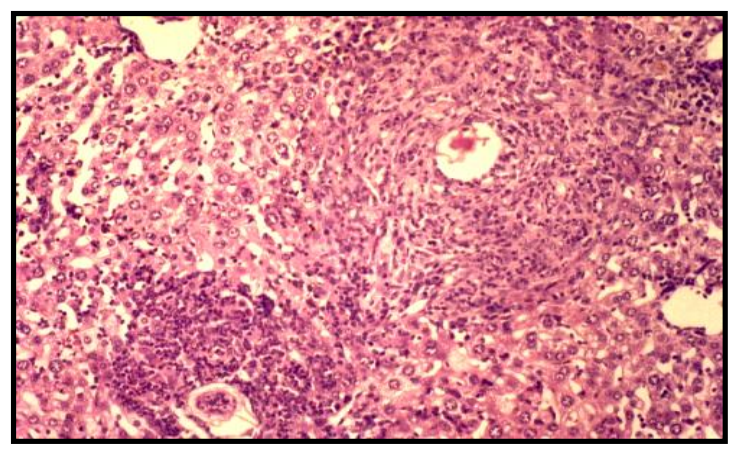

(4f)

Fig. (4): Liver sections of different infected groups to compare the granioloma diameter (stained with Haematoxylin \& eosin stain x 200)

Fig. (4a): Liver section of infected mice control group showing granuloma reactions composed of a mixture of chronic inflammatory cells rich in eosinophils with adjacent hydropic changes and focal atypical hyperplasia of the adjacent hepatocytes. The intact miracidium can be seen inside the ovum.

Fig. (4b): Liver section of Se-ACE-PZQ treated mice, showing a reduction of the hepatic cellular granuloma with regular and well demarcated contour from the surrounding tissue and markedly degenerated miracidium.

Fig. (4c): Liver section of PZQ treated mice, showing a reduction of the hepatic cellular granuloma but to a lesser extent with irregular granuloma contour.

Fig. (4d): Liver section of Se-ACE-Mirazid treated mice, showing reduction in the granuloma diameter and cellular infiltration with partially degenerated miracidium inside the ovum but still less than PZQ treated group.

Fig. (4e): Liver section of Mirazid treated mice showing a large granuloma diameters, the micracidium can be seen inside the ovum.

Fig. (4f): Liver section of Se-ACE treated mice showing a large cellular granuloma diameters with inflammatory cellular infiltration. 



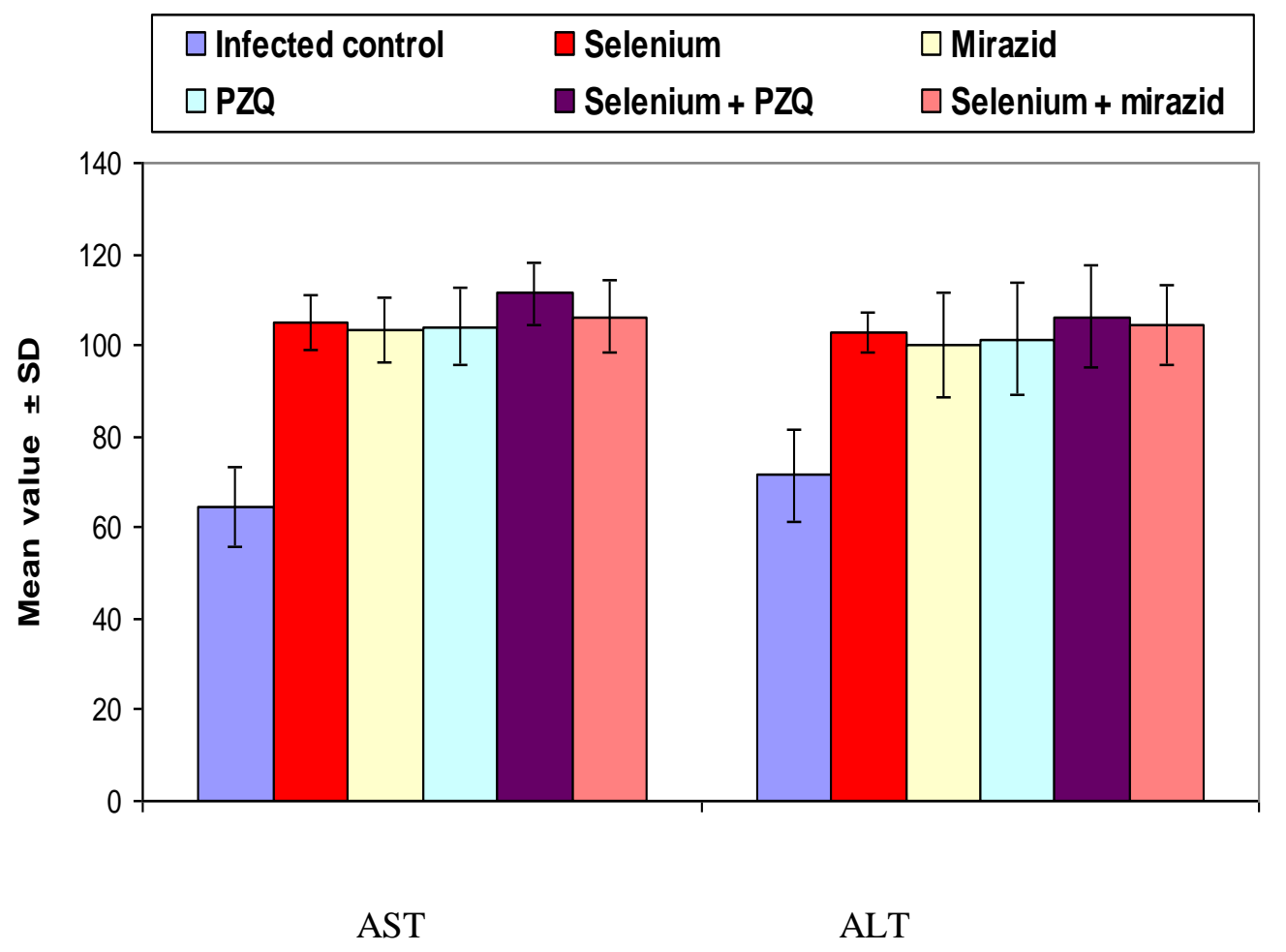

Fig. (5): Mean value of liver ALT and AST in the different studied groups

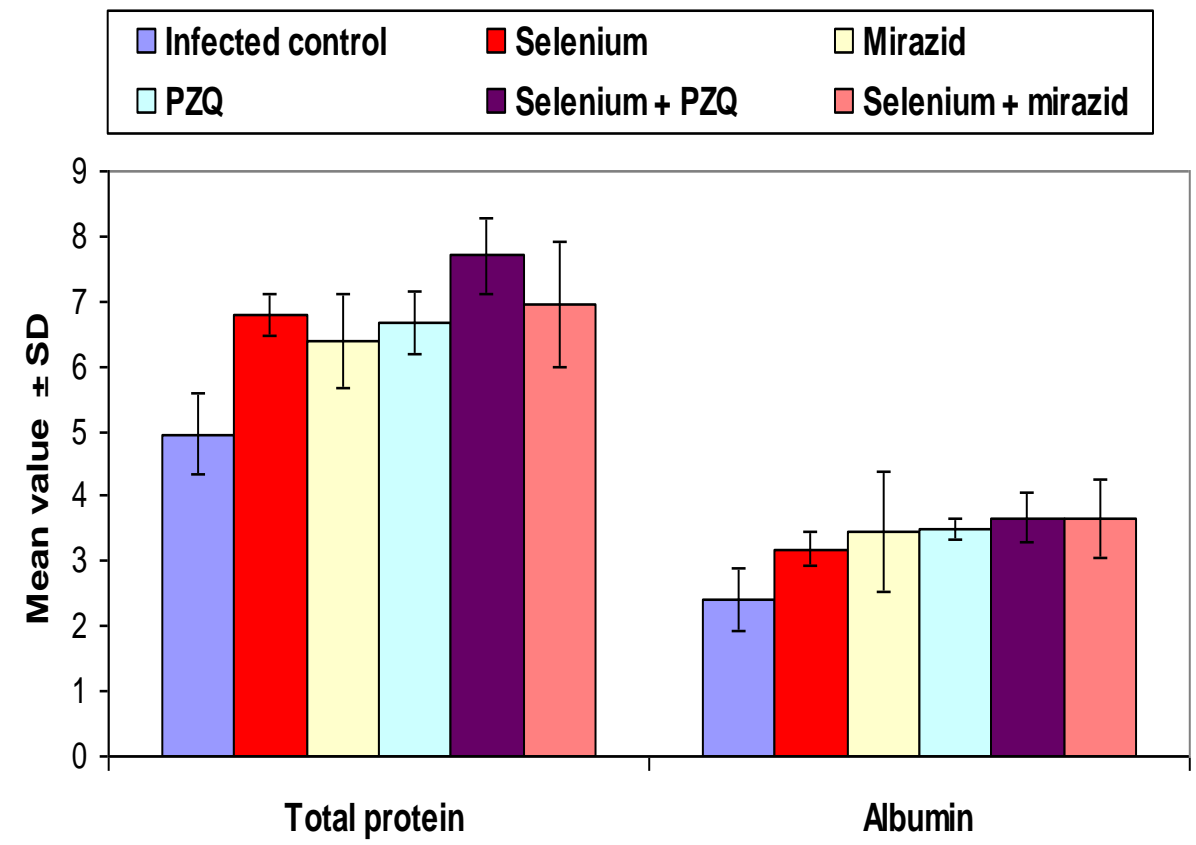

Fig. (6) : Mean levels of liver TP and ALB in the different studied groups. 



\section{Discussion}

The efficacy of PZQ in the present results is in accordance with that reported by Mehlhorn et al. (1981), Liu and Compron (1996), Mahmoud et al. (2002), Martin et al. (2004), Chaiworaporn et al. (2005) and Ebeid et al. (2005) which demonstrated that the curative dose of PZQ causes extensive degeneration of the adult worm in the liver of the treated mice by causing paralysis, uncoupling and shifting from the mesentric vein to the liver where the worms were finally destroyed by the phagocytic system, in contrast to Suleiman et al. (2004) who reported low efficacy of PZQ in treatment of S. mansoni infection and Massoud et al. (2004) who reported that the immature and mature adult stages of $S$. mansoni are more susceptible to MZ than PZQ.

The present results also correlate with those reported by Badria et al. (2001), Abo-Madyan et al. (2004), Massoud et al. (2005), Abdel-Aziz et al. (2006), El-Rigal and Hetta (2006) who showed a significant reduction of the worm burden in $S$. mansoni infected mice treated with MZ $600 \mathrm{mg} / \mathrm{kg}$ body weight for three consecutive days and revealed that the affected worms released their hold on the wall of the mesentric vessels and swept to the hepatic vessels where they were destroyed by autolysis, in contrast to Guirguis and Mahmoud (2003), Botros et al. (2004) and Ramzy et al. (2009) who reported an insignificant reduction of worm load in S. mansoni infected mice and hamsters treated by MZ.

In the same time, the results obtained by De Witt (1957) revealed that, Selenium. Vitamin E- deficient mice, harbor 69\% more of $S$. mansoni worms than mice on adequate diet following exposure to a standard number of cercariae. Olsen $\boldsymbol{e t}$ al. (1997) reported a significant reduction of S. mansoni reinfection in children given multimicronutrients (Vitamin A, B1, B2, B6, C, E and Se. ) compared to children supplemented by placebo in accordance to Farrag and Faddah (1998) who also reported that antioxidants (Se and Vitamin E) can protect the mice from pathogen to a certian level, in addition Davis et al. (1998) suggested that Se supplementation has a beneficial effect during murine infection with Trypanosoma cruzi, where Mahmoud et al. (2002) reported the efficacy of Nigella sativa oil which contains a lots of antioxidants in reducing the number of worms in S.mansoni infected mice .

The role of Se-ACE as an antioxidant in the reduction of worm burden has explained by Yousif and El-Rigal (2004), Ali (2007) and Wang et al. (2009) who reported a reduction of the antioxidant enzymes and Vitamin $\mathrm{E}$ and $\mathrm{C}$ in liver of S. mansoni infected mice pointed out that the toxic substances and free radicals elaborated from $S$. mansoni worms consume the antioxidants and may affect the capacity of the liver to detoxify the 
effect of the toxic endogenous and exogenous compounds.

The present results of ova count are in accordance with Scrimgour and Gajdusek (1985) who stated that PZQ is a powerfull ovicidal drug by killing worms to prevent further ovi position and damage caused by new eggs. Tanaka et al. (1989) reported the high efficacy of PZQ as antischistosomal treatment and suggested that the damage caused by PZQ in the reproductive organs in surviving worms leads to the high reduction in ove count, where Guirguis and Mahmoud (2003) reported an insigificant reduction in worm load and mean number of ova /gm liver in MZ treated S.mansoni infected hamsters, these results are in agreement with the results of Botros et al. (2004), Barakat $\boldsymbol{e t}$ al. (2005), who used mice and hamsters infected with different strains of $S$. mansoni and Botros et al. (2005) who reported very low cure rates and reduction percentages of ova count in MZ with 9.1 $\%$ compared to PZQ with $63.7 \%$, were found in the Egyptian school children and house hold infected with $S$. mansoni.

In contrast, Badria et al. (2001), El-Baz et al. (2003), Sulieman et al. (2004) and Massoud et al. (2005) reported the efficacy of MZ in the reduction of ova count in S.mansoni infection using different doses ranging from $5 \mathrm{mg} / \mathrm{kg}$ body weight to $600 \mathrm{mg} / \mathrm{kg}$ body weight with cure rates ranged from $91.7 \%$ to $97.4 \%$.

Regarding the granuloma number and diameter, the obtained data are in accordance with Botros et al. (2004) and Ebeid et al. (2005) who reported that MZ treatment failed to induce a significant reduction in hepatic schistosomal pathology when compared to infected untreated group, while PZQ therapy resulted in remarkable reduction of granuloma number, size and cellularity with regression of granulomatous inflammatory reaction and Chaiworaporn et al. (2005) who reported a significant reduction in liver granuloma number and diameter of S.mansoni infected mice in response to the curative and sub- curative dose of PZQ.

In contrast Sheir et al. (2001) and Massoud et al. (2005) reported a significant decrease in the mean number as well as the mean perimeter of the mice liver granulomas in infected $\mathrm{MZ}$ treated group, when compared with the infected untreated one. Although Badria et al. (2001) reported a significant reduction in granuloma number and diameter of S.mansoni infected mice after treatment with $\mathrm{MZ}$ and reported also that the rank order of potency in protection against liver cell damage was PZQ>MZ.

Regarding the biochemical assay, our results are in accordance with Al-Sharkawi (1985), El-Aasar et al. (1989), El-Shazly et al. (2001), Hamed and Hetta (2005) and Wagih et al. (2007), who attributed the decrease of transaminases activities in mice liver, and its relative increase in serum, to the decrease in hepatic cell population due to 
liver fibrosis or due to the release of the enzymes from the damaged liver cells into the circulation as a result of increased cell membrane permeability. The observed diminution of AST was more manifested than that of ALT denoting that, although the later is more specific for liver cells, yet it is less sensitive than AST in detecting liver cell damage as reported by Awadalla et al. (1975). Moreover Salah et al. (1976) reported that the presence of more AST in hepatic tissue indicate that the release of ALT is too diluted in the extracellular compartment to cause significant increase in ALT activity in S.mansoni patients. Therefore, variations in the release, destruction or excretion of the two enzymes or an unknown metabolism are probably important contributory mechanisms.

The restoration of ALT and AST activities is supported by Massoud et al. (2004), Hamed and Hetta (2005), El-Rigal and Hetta (2006) and Ali (2007), they reported the restoration of transaminases to the normal levels after treatment with MZ which is similar to the results obtained by Badria et al. (2001) who reported restoration of ALT, AST and protein contents disturbance due to S.mansoni infection after treatment with PZQ and MZ but their results reported that PZQ was more efficient than MZ in restoration of transaminases to the normal levels .

In contrast to the present biochemical results, Abdel Hamid (2004) and Omar et al. (2005) reported that, the treatment of $S$. mansoni infected albino rats with PZQ caused a significant side effects estimated by elevation of ALT and AST activities, elevation of creatinine, total lipids, cholesterol, triglycerides and reduction of TP, ALB, globulin and ascorbic acid.

The reduction in the TP and ALB obtained correlates with those of El-Rigal and Hetta (2006) and Mahmoud et al. (2002) who reported a significant reduction of ALB in $S$. mansoni infection due to the switching of the ALB gene transcription to alpha -fetoprotein. Amal et al. (1979), El-Zayadi et al. (1991), El-Fakahani et al. (1993), Van Raaij et al. (1994) and Farouk (2000), reported the reduction of TP and ALB after S. mansoni infection due to reduced anabolism and increased catabolism in the body, hence malnutrition and/or malabsorption may contribute to the decrease in biosynthesis of ALB. It was clearly noticed that the addition of SeACE to PZQ and MZ increases the antischistosomal activity of both of them in parasitological, histopathological and biochemical aspects.

Parasitologically, the addition of Se-ACE, increased the potency of PZQ and MZ in reducing the worm burden and ova count/gm liver, which correlate with Roche et al. (1994) who determined a seleium dependent antioxidant enzymes, glutathione peroxidase and glutathione reductase protective role against schsitosomal infection. Mahmoud et al. (2002) reported the high efficacy of 

Nigella sativa oil as an antioxidant in combination with PZQ in reduction of the worm load and ova count in $S$. mansoni infected mice and Ali (2007) reported depletion of antioxidant enzymes, viatmin $\mathrm{C}$ and $\mathrm{E}$ in the liver of mice infected with S.mansoni and reported the importance of antioxidants in treatment of schistosomal infection and reduction of worm load and ova count.

Histopathologically, Ali et al. (1991) and Mahmoud et al. (2002) reported the efficacy of PZQ in reducing the granulomas diameter and proved that this efficacy increased by adding different antioxidants as a co-treatment, where Soliman and El-Shenawy (2003), Feldman et al. (2007) and Hessein et al. (2008) reported the efficacy of superoxide scavenger diisopropyl salicylate, Silymarine and Nigella sativa oil as antioxidants in combination with PZQ in modulating the pathological profile of schistosomiasis by reducing the severity of the hepatic granulomas and other histopathological changes.

Biochemically, the obtained results correlate with those of Yamazaki et al. (1993) who found that, in rats, vitamin $E$ supplementation during hepatitis delay the elevation of liver enzymes and reduction of ALB, El-Sokkary et al. (2002) and Metwally (2006) reported the importance of the antioxidants in correction of ALT, AST and TP disturbance caused by S.mansoni infection, where Wagih et al. (2007) reported a significant reduction in the antioxidant enzymes as well as the antioxidant vitamins $\mathrm{A}, \mathrm{C}$ and $\mathrm{E}$ and increase in serum ALT in patients infected with S. mansoni and recommended the usage of antioxidant supplementations as a co-treatment in combination with the antishistosomal chemotherapy and Othman et al. (2008) reported the efficacy of PZQ in combination with the antioxidant enzyme Q-10 to improve the liver function in S.mansoni infection.

\section{Conclusion:}

1. PZQ still the first choice $S$. mansoni chemotherapeutics agents with good levels of safety regarding the liver biochemical and histopathological parameters.

2. MZ showed good levels of safety with a moderate antischistosomal activity after PZQ, regarding liver biomedical and histopathological parameters.

3. Se-ACE showed a couraging criterion as a co- treatment potentiating the effect of the antischistosomal medications through its antioxidant activity.

\section{References:}

Abdel-Aziz M M, Abbas A T, Elbakry K A, Toson E A and El-Sherbiny M (2006): Immune response in mice infected with $S$. mansoni and treated with myrrh. J. Med. Sci., 6(5): 858-861.

Abdel-Hamid H F (2004): Investigation of induced biochemical and histopathological parameters of acetonitrile extract of Jatropha 

carcus in albino rats. J. Egypt. Soc. Parasitol., 34(2): 397-406.

Abo-Madyan A A, Morsy T A and Motawea S M (2004): Efficacy of myrrh in the treatment of schistosomiasis (Haematobium and mansoni) in Ezbet El-Bakly, tamyia center, El-Fayoum Governorate. Egypt. J. Egypt, Soc., 34:423-446.

Ali H F (2007): Evaluation of antioxidants effect of citrus reticulate in S. mansoni infected mice mice. Trends in Medical Research, 2(1): 37-43.

Ali M Q, Doehring E S, Abdel-Rahim T M, Schlake J, Kardorff R, Frank D and Kaiser C (1991): Ultrasongraphical investigation of periportal, fibrosis in children with S.mansoni infection, reversibility of morbidity seven months after treatment with praziquatel. Am. J. Trop. Med. Hyg., 44: 444.

Al-Sharkawi I M (1985): Studies on the effect of thiola on bilharzial liver treated with antibilharzial drug. Ph.D. Thesis, Fac. Sci., Tanta Univ. Egypt.

Amal I M, Raga A W, Guirgis N H, ElGazayell I $M$ and Hamza $S$ (1979): Biochemical studies on bilharzial liver in experimental animals. Egypt. J. Physiol. Sci., 6(1/2): 37-44.

Awadalla H N, Sherif A F, Shafei A Z, Khalil, H A and Guirgis F K (1975): Enzyme levels in homogenates of liver from mice infected with $S$. monsoni and from uninfected mice. Int. J. Parasitol., 5: 27-31.

Badria F, Abou-Mohamed G, El-Muafy A, Massoud A and Salama O (2001): Mirazid A new schistosomicidal drug. Pharmaceut. Biol., 39 (2): 127-131.

Barakat R, El-morshedy $H$ and Fenwick A (2005): Efficacy of myrrh in the treatment of human schistosmiasis. Am. J. Trop. Med. Hyg., 73:365-367.
Boros D L and Warren K S (1970): Delayed hypersensitivity type III: granuloma formation and dermal reaction induced of elicited by a soluble factor isolated from $S$. mansoni eggs. J. Exp. Med., 132: 488-507.

Botros S, William S, Ebeid F, Cioli D, Katz N, Day T A and Bennett J L (2004): Lack of evidence for an antischistosomal activity of myrrh in experimental animals. Am. J. Trop. Med. Hyg., 71:206-210.

Botros S, Saued H, El-Dusoki H, Sabry H, Rabie I, El-Ghannam M, Hassanein M, Abd El-Wahab Y and Engels D (2005): Efficay of mirazid in comparison with praziquantel in Egyptian S.mansoni infected school children and households. Am. J. trop. Med. Hyg., 72(2):119-123.

Chaiworaporn R, Maneerat Y, Rojekittikhun W, Ramasoota P, Janecharut T, Mastuda H and Kitikoon V (2005): Therapeutic effect of subcurative dose of praziquantel on $S$. mansoni infected mice and resistance to challenge after treatment. Southeast. Asian. J. Trop. Med., 36 (4): 846-852.

Cheever A W (1968): Conditions affecting the accuracy of potassium hydroxide digestion techniques for counting $S$. mansoni eggs in tissues. Bull. WLD. With. Org., 39:328-331.

Davis C D, Brooks L, Calisi C, Bennett B J and Mc Elroy, D M (1998): Beneficial effect of Selenium supplementation during murine infection with Trypanosome cruzi. J. Parasitol., 84(6): 1274-1277.

De Witt W B (1957): Experimental S. mansoni in mice maintained on nutritionally deficient diets. Survival and development of S. mansoni in mice maintained on Torula yeast diet deficient in factor 3, vitamin $\mathrm{E}$ and cystine. $\mathrm{J}$. Parasitol., 43: 129-135. 

Doumas $B \quad T$ and Bigges $H \quad G$ (1972):

Determination of Serum Albumin. Academic Press., New York, 7:175.

Duvall, R.H. and De Witt, W.B. (1967): An improved perfusion technique for recovering adult schistosomes from laboratory animals. Am. J. Trop. Med., 16:483-486.

Ebeid F A, Mahmoud S S, Botros S S and Badawy A A (2005): Evaluation of the antibilharzial activity of mirazid versus praziquantel against S. haematobium. J. Egypt. Endem. Dis., 27:25-37.

El-Aasar A A, El-Merzabani M M, Zakhary N I, Farag H I, Abdeen A M, Abd El-Slam I and Mokhtar N M (1989): Biochemical and biophysical studies on schistosomal liver of mice. Egypt, J. Bilh., 11:19-33.

El-Baz M A, Morsy T A, El-Bandary M M and Motawea S M (2003): Clinical and parasitological studies on the efficacy of Mirazid in treatment of $S$. haematobium intatoon, Etsa. Center, El-Fayoum Governorate. J. Egypt. Sco. Parasitol., 33(3): 761-776.

El-Fakahani A F M, Abdalla K F, El-Hadi H M, Abd-El-Azez S M and Afifi L M (1993): The effect of Praziquantel treatment on the liver function, worm burden and granuloma size using two drugs regimen in murine S.mansoni infection. J. Egypt. Soc. Parasito., 23:877-886.

El-Hawey A M, Massoud A M, El-Radieby A, Rozeik M S and Nassarm M O (1990): Side effects in praziquantel in bilharzial children on a field level. Egy. J. Sco. Parasitol., 20:599-605.

El-Rigal N and Hetta M H (2006): Effect of citrus reticulata on serum protein fraction of mice after S. mansoni infection. J. of Applied Science., 6(7): 1447-1455.

El-Shazly A M, Motawea S M, El-Gilany A, Salam O, Massoud A and Caballah M (2001): Apreliminary study of the molluscicidal activity of Myrrh. J. Environ. Sci., 21(5): 153-162.
El-Sokkary G H, Omar H M, Hassanein A F, Cuzzocrea S and Reiter R J (2002): Melatonin reduces oxidative damage and increases survival of mice infected with S. mansoni. Free Rad. Biol., Med. 32: 319-332.

El-Zayadi A, Mohran Z, Hasseb, N, Nagy, N and Dabbour, H (1991): Short term course of corticosteroids in the treatment of resistant ascites complicating schistosmal liver disease. Am. J. Gastroenterol., 86 (1): 53-56.

Farouk H (2000): Study of some influential factors on adenylate energy charge and urea cycle enzyme in mice liver. Ph.D. Thesis, Faculty of Science, Mansoura Univ. Egypt.

Farrag E and Faddah L M (1998): Selenium and vitamin E supplementation provide a good defense mechanism against oxidative stress caused by Schistosoma infection. Bull. Egypt. Sco. Physiol. Sci., 18(1): 394-405.

Feldman G M, Naples $\mathbf{J}$ M and Seed J L (2007): Effects of anethol dithiolthione and 2(3)-tert-butyl-4-hydroxyanisol on schistosome granuloma formation. Parasite Immunology, 7(6): 567-573.

Guirguis F R and Mahmoud S S (2003): On the efficacy of a new antischistosomicidal drug (Mirazid) against S. haematobium and S.mansoni, an in vivo study. J. Egypt. Ger. Zool., 42:89-98.

Hamed M A and Hetta M H (2005): Efficacy of citrus reticulate and Mirazid in treatment of Shistosoma mansoni. Memorias do Institute Oswald. Cruz., 100(7): 771-778.

Hessien M, El-Sharkawi I, El-Barbary A and Beltagy D M (2008): Regresseion of theioacetamide, alcohol and schistosomiasis induced liver fibrosis in mice by Silymarin. Turk. J. Biochem., 33 (4): 131-137.

Liu L X and Compron A (1996): Paralysis due to schistosomiasis. N. Engl. J. Med. Jun., 23 (334):

1548-1549. 

Mahmoud A A E and Warren K S (1974): Anti-inflammatory effects of tarteremtic and niridazole suppression of Schistosoma egg granuloma J. Immuol., 112: 222-228.

Mahmoud M R, Zhciry M M and Nosseir M M (2002): Effect of combined chemotherapy and anti-inflammatory drugs on murine schistosomiasis. Ar. Znei. Mittel. Fors. Chung., 53(4): 294-301

Martin F, Penet M, Malerque, F, Lepidi H, Dessein A, Galland F, Reggi M, aquet N P and Garib B (2004): Vanin mice show decreased NSAID and schistosomiasis induced intestinal inflammation associated with higher glutathione stores. J.Cli. Invest., 113:591-597.

Massoud A M, El-Ebiary F H, Abou-Gamra M M M, Mohamed G F and Shaker S M (2004): Evaluation of schistosomicidal activity of myrrh extract : Parasitological and histological study. J. Egypt. Soc. Parasitol., 34(3): 1051-1076.

Massoud A M, El-Ebiary F $\mathbf{H}$ and Ibrahim S H (2005): Light microscopic study of effect of new antischistosmal drug (Myrrh extract) on the liver of mice. J. Egypt. Soc. Parasitol., 35:971988.

Mehlhorn H B, Becker P, Andrews H, Thomas and Frenkel J K (1981): In vivo and in vitro experiments on the effects of praziquantel on S. mansoni: a light and electron, microscopic study. Arzhneimittel for Schung., 31:544-554.

Metwally N S (2006): Potency of Allium sativum and Allium cepa oils against $S$. mansonia infection in mice. J. Egypt. Med. Hos., 23:319-332.

Omar A M A, El-Mesallamy Gh El-Said and Eassa Sh (2005): Comparative study of the hepatotoxic, genotoxic and carcinogenic effects of praziquantel distocide and the natural myrrh extract mirazide adult male albino rats. J. Egypt. Soc. Parasitol., 35(1): 313-329.

Olsen A, Thiong'o F W, Ouma J H, Mwaniki D, Michaelsen F, Friis $H$ and Geissler P W (1997): Effect of multimicronutrient supplementa-tion on helminth reinfection: Arandomized trail in keynian school children. Trans. R. Soc. Trop. Med. Hyg., 97 (1): 109114.

Othman A A, Shoheib Z S, Abdel-Aleem Gh $A$ and Shareef M M (2008): Experimental Schistosomal hepatitis. Protective effect of coenzyme Q10 against the state of oxidative stress. Exp. Parasitol. J., 120(2): 147-155.

Pearson R D and Guerrant R L (1983): Praziquantel, Amajor advance in antihelminthic therapy. Ann. Intem. Med., 99: 195-198.

Peters T (1968): Determination of total protein. Clin. Chem., 14:1147.

Ramzy F, Mahmoud S and William S (2009):

Further assessment of mirazid as antischistosomal drug in experimental $S$. haematobium. J. Pharmacut. Biol., 22: 120-126.

Roche C, Williams D L, Khalife J, Lapresle T, Capron A and Pierce R J (1994): Cloning and Characterization of the gene encoding $S$. mansoni glutathione peroxidase. Gene., 138:149-152.

Salah L A, Kheirldin A A, Mansour M M and Hussein F (1976): Levels of some serum enzymes in patients with schistosomiasis. Am. J. Trop. Med. Hyg., 79:270-274.

Schmidt E (1963): Colorimetric determination of SGot and SGpt. Enzyme. Boil. Clin., 3:1-53.

Scrimgour E M and Gajdusek D C (1985): Involvement of central nervous system in S.mansoni and S.heamatobium infection. View. Brain., 108:1023-1038.

Sheir Z, Nasr A A, Massoud A and Salama O (2001): Asafe, effective, herbal antischistosomal 

Studies on the effect of .....

therapy derived from Myrrh. Am. J. Trop. Med.

Hyg., 5(2): 6-9.

Smithers S R and Terry R J (1965): Infection of laboratory hosts with cercariar of S. mansoni and the recovery of adult worms Parasitol., 55: 695-700.

Soliman M F M and El-Shenawy N S (2003): Evaluation of the protective effect of two antioxidative agents in mice experimentally infected with S. mansoni Haematological and histopathological aspects., Pakistan J. Biol. Sci., 45:887-897.

Sulieman M I, Karim E I, Ibrahim K E E, Saad A M, Mohammed A E, Ahmed, B M and Suleiman, S M (2004): Antischostosomal effects of praziquantel, its alkaline hydrolysis and sun decomposed products on experimentally S.mansoni infected albino mice.

Efficacy assessment based on clinicopathological finding. J. Egypt. Soc. Parasitol., 34(1): 131-142.

Tanaka M, Ohamac H, Ulsunomiya H, Yakeshi N, Yuji Irie and Yasuraoka K (1989): A comparison of the antischistosomal effect of levo and dextro-praziquantel on $S$. japonicum and S. mansoni mice. Am. J. Trop. Med. Hyg., 41(2): 198-203.

Van Raaij M T M, Bakker E, Nieveen M C, Zirkand Z H and Vanden E J M (1994):

Energy status and free fatty acid patterns in

tissue of common carp. (Cyprinus Carpio ) and (Oncorhynchus mykiss) during severe oxygen restriction. Comp. Biochem. Physiol., 109:766767.

Von Lichtenberg F C (1962): Host response to eggs of $S$. mansoni. granuloma formation in the sensitized laboratory mouse. Am. J. Pathol., 41:711-731.

Wagih A, El-Shazly Sh and Ismail H (2007):

Effect of fascioliasis and S.mansoni on the antioxidant defense mechanisms. J. Tanta. Med. Sci., 2:56-66.

Wang C, Wu Y, Qin J, Sun $H$ and He $H$ (2009): Induced susceptibility of host is associated with an impaired antioxidant system following infection with Cryptosporidium parvum in Se. Deficient mice. Plos. J., 4(2): 46. Yamazaki K, Ohyama H, Kurata $K$ and Wakabayashi T (1993): Effects of dietary vitamin $\mathrm{E}$ on clinical course and plasma glutamic oxaloacetic transaminase and glutamic pyruvic transaminase activities in hereditary hepatitis of LEC rats. Am. Assoc. Lab. Anim. Sci., 43(1): 61-67.

Yousif M F and El-Rigal N S (2004): Cglycosyl flavon of clerodendrum splendens $\mathrm{G}$. Don and antioxidant activity in schistosomeinfected mice. Egypt. J. Biomed. Sci., 14: 128137. 
دراسات على تأثثر مضاد الأكسدة سيلينيوم - أ ج هـ بعد المعالجة بالبرازيكوانتل والميرازيد فى الفئران المصابة ببلهارسيا المستقيم

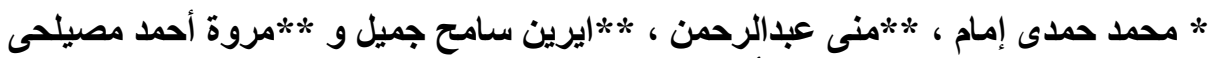

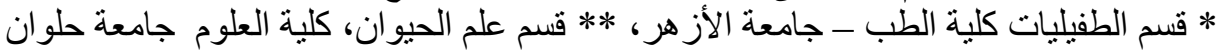

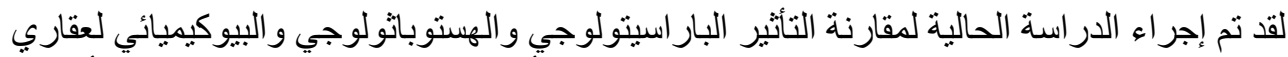

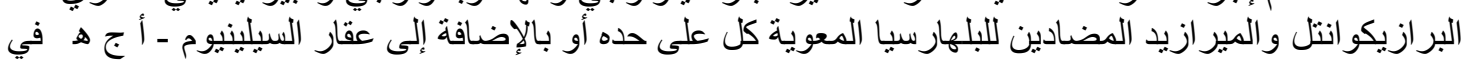

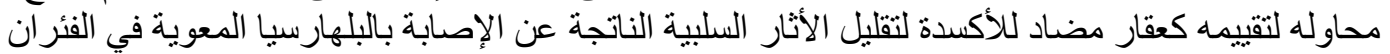
البيضاء.

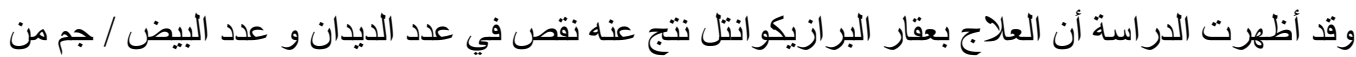

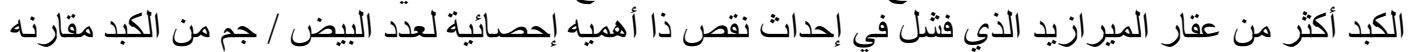

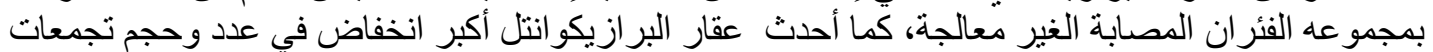

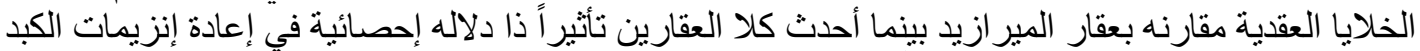

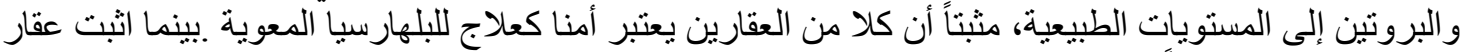

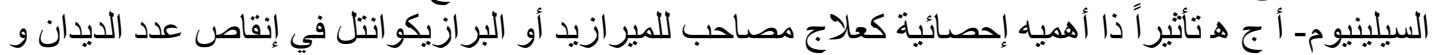

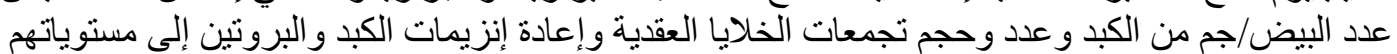
الطبيعية.

\section{وقد خلصت هذه الدراسة إلى الأتي :}

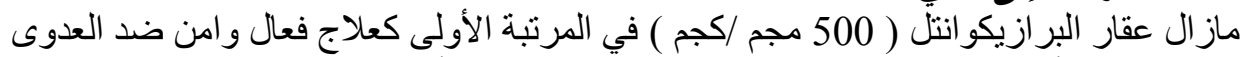

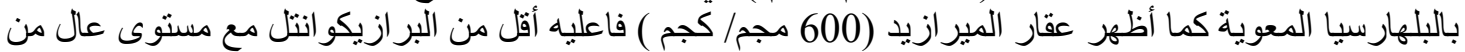

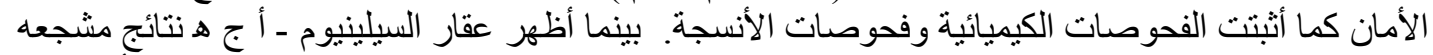
كعقار مساعد للمير ازيد و البرازيكو انتل ضد العدوى العدى بالبلهارسيا المعوية عن طريق خو اصنه كمضاد للأكسدة. 